\title{
Hiring Graduates for Marketing - Advantages, Disadvantages and Competency Requirements
}

\author{
Radim Dušek ${ }^{1, *}$, Monika Hrubá ${ }^{1}$, Karolína Brodská $^{1}$, Petra Skálová1 \\ ${ }^{1}$ Institute of Technology and Business, Faculty of Corporate Strategy, Department of Tourism and Marketing, Nemanická 436/7, \\ 37010 České Budějovice, Czech Republic
}

\begin{abstract}
The selection of suitable employees is becoming more and more demanding because of the increasing number of job applicants that want to get into a marketing career. The aim of this contribution is to find out which marketing competencies a competent graduate of economics should possess to be attractive for marketing related jobs in SMEs in the Region of South Bohemia, as well as to identify the positives and negatives of hiring such graduates. Based on data obtained from 93 SMEs with their own marketing department, the desired competent graduate for marketing related jobs can be described as a communicative and creative individual with the ability to analyse information. The main advantages of hiring graduates include creativity, the ability to work with modern technologies and/or enthusiasm for learning. On the other hand, a lack of experience and/or the longer training time are the main disadvantages of hiring fresh graduates for marketing-related jobs.
\end{abstract}

Keywords: competency models; marketing competencies; graduates; HR; SME

\section{Introduction}

In developed countries, major efforts have been made by universities to prepare graduates of business or economic degrees, and who want to be marketers, to meet actual labour market requirements. Now, more than ever, if candidates for marketing related jobs, including university economics graduates, want to start a successful career in, for example the marketing communication field, they should possess key competencies, as determined by employers. These requirements are no longer based only on theoretical knowledge, but especially on higher level abilities, ones which provide a framework for the behaviour and skills that are expected of competent marketers in various types of marketing specializations $[1,2,3]$. Key competencies can be defined as a generic complex of knowledge, values and attitudes, but primarily life skills, such as problem solving, communication, collecting and analysing information, ability to work independently, leadership, creativity, ability to cooperate effectively, and the desire to participate in lifelong learning [4, 5]. These competencies allow individuals to act appropriately and efficiently within various professional and personal life situations. They represent and incorporate a wide range of long-term qualifications and requirements for a flexible response to changing labour market demands, as well as ensure maximum performance in the defined tasks [6].

The selection of suitable employees is becoming more and more demanding because of the increasing number of job applicants that want to get into a marketing career. Nowadays, due to the requirements for matching the needs of companies with individual employee abilities, companies are increasingly using a competency-based approach to selecting the most suitable candidate. A competency-based approach involves the specification of the desired framework of the individuals' key competencies for specific positions by means of a competency model as a basis for the selection of suitable applicants for a given position [7-9].

A competency model defines a combination of priority skills, abilities and knowledge, that is, individual competencies necessary to perform the tasks related to a specific position within an organization, for example in the marketing department. Competency models can be divided into two basic types: a) generic - for universal application throughout a company; and b) specific - wherein competencies that are a prerequisite for the required performance of a given employee in a specific position within a company are defined $[10,11]$.

To find component and capable potential employees for marketing related jobs, the recommended competency model should consist of the following particular groups of desired key competencies, each of which should be tested on job applicants during the hiring process [12-17]:

\footnotetext{
* Corresponding author: dusek@mail.vstecb.cz
} 
1. Competencies related to problem solving:
a. Creative thinking
b. Negotiating skills
c. Public speaking
d. Analysing and assessing information

2. Social (interpersonal) competencies:
a. Ability to communicate
b. Ability to work in a team
c. Ability to lead and motivate people

3. Self-management:
a. Ability to work independently
b. Ability to work under pressure
c. Ability to manage a budget

Most of these competencies are behavioural, so if students have certain basic individual capabilities, their competencies can be developed throughout higher education [1]. With regards to the development of marketing competencies in universities and the preparation of students for their future successful marketing careers, there are plenty of methods that have been proven to help. These include case studies [18], business simulation games [19, 20] or projectbased learning $[21,22]$.

The latter is considered to be one of the most suitable pedagogical tools for the development of students' marketing competencies. This approach is characterized by the creation of student research teams that work on long-term projects (usually one or two semesters) connected to real world business practice with the purpose of solving the actual business tasks and problems $[23,24]$.

\section{Methodology}

The aim of this contribution is to find out which marketing competencies a competent graduate of economics should possess in order to be attractive for marketing related jobs in small and medium-sized enterprises (SMEs) in the Region of South Bohemia. A partial goal is to identify the positives and negatives associated with employing graduates in marketing departments.

Following an analysis of secondary resources [12-17], the research focused on a set of eight marketing competencies, namely:

1. Creative thinking;

2. Communication;

3. Working independently;

4. Effective team collaboration;

5. Negotiating skills;

6. Analysing and assessing information;

7. Public speaking;

8. Ability to work under pressure.

The following criteria were defined for the selection of suitable respondents from among SMEs:

a) companies with 25 - 249 employees;

b) companies with a marketing department;

c) companies in the Region of South Bohemia.

The minimum number of 25 employees was set due to the assumed existence of marketing departments in such SMEs. The data was collected in 2018 - 2019 on the basis of a questionnaire survey conducted among 93 companies that met the aforementioned requirements. Data was primarily obtained from those persons responsible for recruitment $-\mathrm{HR}$ managers or directors in some cases. Using a 5-point scale (from 1 to 5, where $1=$ very significant, $2=$ significant, $3=$ important, $4=$ not significant, 5 = unimportant), the respondents evaluated the importance of specific marketing 
competencies. Subsequently, in the open-ended question, the respondents also defined their idea of the optimal behaviour of a competent graduate for each specific marketing competency. In the second part of the questionnaire, respondents were asked to identify, from lists of 15 , the advantages and disadvantages of employing graduates. They could choose a maximum of 4 options from each group. For the statistical analyses, STATISTICA 9 software was used. As the obtained data do not follow normal (Gaussian) distribution, only a non-parametric test was used for the analysis thereof (Friedman ANOVA).

\section{Results and Discussion}

\subsection{Preferred marketing competencies}

Using the Friedman ANOVA to determine the significance of a specific marketing competence, the following hypotheses were tested at the significance level of $\alpha=0.05$ :

$H_{0}$ : The average significance of the individual marketing competencies determined by the surveyed companies is identical.

\section{$H_{A}$ : non $H_{0}$}

Results of Friedman ANOVA:

ANOVA $=237.5801 ; \mathrm{df}=8 ; \mathrm{N}=93 ; \mathrm{p}$-value $=0.000$

Taking into consideration the obtained $\mathrm{p}$-value, the zero hypothesis is therefore rejected. This means that in the process of finding a competent graduate for a marketing department, there are identifiable differences in the companies' perception of the marketing competencies required. The average significance of every competency of the analysed group of marketing competencies based on the SMEs points of view are presented in Table 1. The closer the individual means are to 1 , the greater the importance the specific competency has to employers.

Table 1. Importance of marketing competencies (means, $n=93$ )

\begin{tabular}{|l|c|c|}
\hline Marketing competencies & $\begin{array}{c}\text { Arithmetic } \\
\text { mean }\end{array}$ & $\begin{array}{c}\text { Standard } \\
\text { deviation }\end{array}$ \\
\hline Creative thinking & 1.27 & 0.43 \\
\hline Assessing and analysing information & 1.34 & 0.54 \\
\hline Working independently & 1.39 & 0.57 \\
\hline Communication & 1.48 & 0.61 \\
\hline Effective team collaboration & 1.67 & 0.69 \\
\hline Ability to work under pressure & 1.93 & 0.77 \\
\hline Public speaking & 2.56 & 0.73 \\
\hline Negotiating skills & 2.83 & 0.87 \\
\hline
\end{tabular}

Source: Author.

Based on the results, it is possible to define the basic profile of a desired competent graduate for marketing related jobs as follows: a communicative individual with the ability to provide original and unexpected solutions to problems, both independently and as a member of a team. When solving problems, the graduate should be able to obtain necessary information, purposefully and efficiently, from various resources, find a core message, and distinguish between relevant and irrelevant information. Also of importance is the ability to work towards a common predefined goal in cooperation with co-workers and comply with deadlines. On the other hand, the competent graduate does not have to be a good public speaker and/or have the ability to negotiate.

\subsection{Advantages and disadvantages of hiring graduates}

Employing graduates of universities of economics has many advantages, which is why SMEs hire them, in particular for entry level marketing jobs. The most important advantages for the surveyed SMEs are presented in Figure 1. Notably in the field of marketing, hired graduates see everything from a different angle, come up with different and creative ways and ideas, or point out mistakes that were ignored in the past. They are often skilled in working with modern technologies and social networks, which opens up new ways of marketing, especially for small companies. Moreover, graduates are very enthusiastic about learning new things and usually pay more attention to their tasks because they are at the start of their careers. 


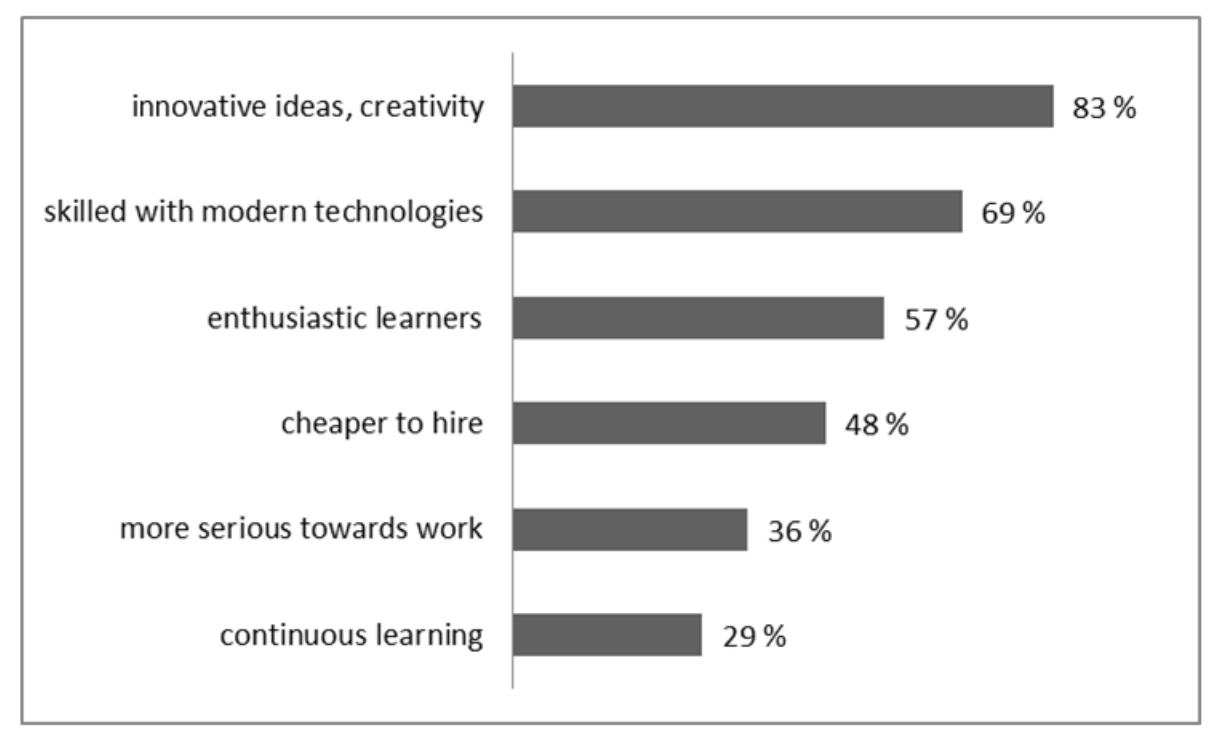

Figure 1. Advantages of hiring graduates $(n=93)$

Source: Author.

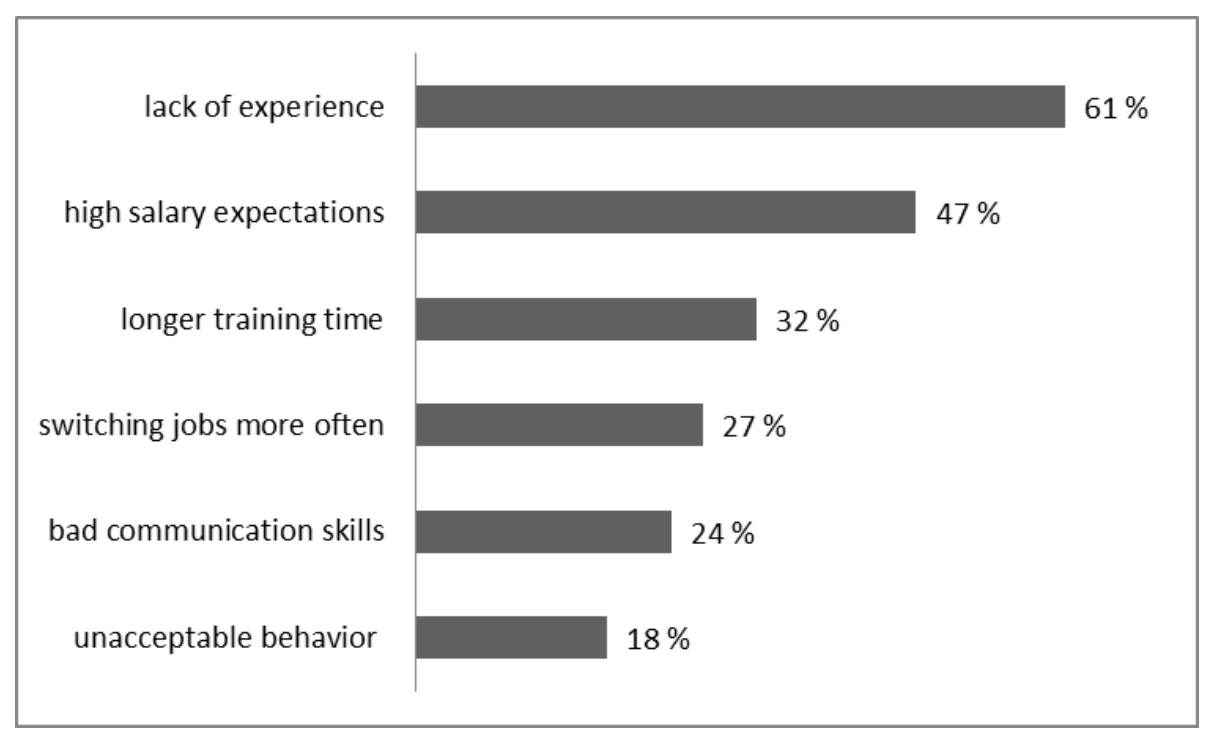

Figure 2. Disadvantages of hiring graduates $(n=93)$

Source: Author.

It is clear that there are also disadvantages for the surveyed SMEs in hiring graduates for marketing departments (see Figure 2). Sometimes graduates of universities of economics have no work experience in the marketing industry, so it takes a longer time to develop their skills. As a result, the management will have to understand that the hired graduate will not immediately generate positive change within the organization. That is why every newly hired graduate has to be trained properly, but this period may be longer than in the case of more experienced employees. Unfortunately, one of the main problems of hiring fresh graduates are their high salary expectations. Sometimes they cannot understand that they have just joined a company and therefore cannot expect to be paid like an experienced marketing communications specialist. At the same time, young people are very often searching for the right career and salary is an important reason for switching jobs, every year if needs be.

\section{Conclusion}

The aim of this contribution was to find out which marketing competencies a competent graduate of economics should possess in order to be attractive for marketing related jobs in SMEs in the Region of South Bohemia, as well as to identify the positives and negatives of hiring such graduates. Based on data from 93 SMEs with their own marketing department, the appropriate candidate can be described as a communicative individual with the ability to provide original and unexpected solutions to problems, both independently and as a member of a team. When solving problems, the graduate should be able to obtain necessary information, purposefully and efficiently, from various resources, find a core message, and distinguish between important and unimportant information. Also of importance is the ability to work towards a 
common predefined goal in cooperation with co-workers and to comply with deadlines. On the other hand, the competent graduate does not have to be a good public speaker and/or have the ability to negotiate.

It is clear that for the surveyed companies, hiring graduates for their marketing departments has its advantages and disadvantages. The main advantages include creativity, ability to work with modern technologies and/or enthusiasm for learning. On the other hand, the lack of experience, high salary expectations and longer training time are the main disadvantages of hiring fresh graduates for marketing-related jobs.

\section{References}

1. M. Hay, Business schools: a new sense of purpose. Journal of Management Development. 27(4), 371-378 (2008)

2. V. Vojtko, R. Dušek, Filling the gap between theory and practice by business simulation games. Conference Proceedings of the 20th Annual International Conference Enterprise and Competitive Environment. Mendel University in Brno, 908-918 (2017)

3. M. Tomlinson, 'The degree is not enough': students' perceptions of the role of higher education credentials for graduate work and employability. British journal of sociology of education. 29(1), 49-61 (2008)

4. M. Armstrong, Armstong's Handbook of Human Resource Management Practice. Philadelphia: Kogan Page (2011)

5. A. Wiek, L. Withycombe, C. L. Redman, Key competencies in sustainability: a reference framework for academic program development. Sustainability Science. 6(2), 203-218 (2011)

6. T. Weiss, S. Kolberg, Coaching Competencies and Corporate Leadership. Florida: CRC Press (2003)

7. D. D. Dubois, W. J. Rothwell, Competency-Based Human Resource Management. California: Davies-Black Publishing (2004)

8. C. J. Gonsalvez, F. L Calvert, Competency-based Models of Supervision: Principles and Applications, Promises and Challenges. Australian Psychologist. 49(4), 200-208 (2014)

9. M. A. Campion, A. A. Fink, B. J. Ruggeberg, L. Carr, G. M. Phillips, R. B. Odman, Doing competencies well: best practices in competency modeling. Personnel Psychology. 64(1), 225-262 (2011)

10. S. Sanghi, The handbook of competency mapping: understanding, designing and implementing competency models in organizations. New Delhi: Response Books (2004)

11. D. Liebenow, S. Uedelhoven, M. Stricker, J. Nachtwei, Quality in Competency Management: An Explorative Study to Develop a Benchmark for Competency Modeling and Competency Models. Zeitschrift fur Arbeits-und Organisationspsychologie. 64(2), 120-148 (2020)

12. G. W. Stevens, A Critical Review of the Science and Practice of Competency Modeling. Human resource development review. 12(1), 86-107 (2013)

13. J. Hadrich, New Key Competencies for Authorities, Companies and their Managers Part 2: Obstacles and Success Factors of modern Leadership. Deutsche Lebensmittel-Rundschau. 116(5), 186-196 (2020)

14. J. M. Loveland, S. A. Thompson, J. W. Lounsbury, D. Dantas, Is diffusion of marketing competence necessary for a market orientation? A comparative investigation of marketing managers and their defining traits. Marketing Intelligence \& Planning. 33(3), 469-484 (2015)

15. DQ. Xin, X. Zhao, The Construction of College Students Self-marketing Competency Model. Recent advance in statistics application and related areas, vols I and II. Proceedings from the 2nd Conference of the International Institute of Applied Statistics Studies, Qingdao, China (2009)

16. M. Rieckmann, Future-oriented higher education: Which key competencies should be fostered through university teaching and learning? Futures. 44(2), 127-135 (2012)

17. S. Nwankwo, A. Gbadamos. Entrepreneurship Marketing: Principles and Practice of SME Marketing. Oxon: Rouletge (2020)

18. E. Anderson, B. Schiano, Teaching with cases: a practical guide. Harvard Business School Publ, Boston, Mass (2014)

19. S. R. Tiwari, L. Nafees, O. Krishnan, Simulation as a pedagogical tool: Measurement of impact on perceived effective learning. The International Journal of Management Education. 12(3), 260-270 (2014)

20. M. Pratt, S. Hahn, Effects of Simulation on Student Satisfaction With a Capstone Course. Journal of Hospitality \& Tourism Education. 27(1), 39-46 (2015) 
21. W.N. Bender, Project-based learning: differentiating instruction for the 21st centrury. Thousand Oaks: Corwin (2012)

22. R. Maltese, Project Based Learning: 25 Projects for 21st Century Learning. Indianapolis: Dog Ear Publishing (2012)

23. M. Almulla, The Effectiveness of the Project-Based Learning (PBL) Approach as a Way to Engage Students in Learning. Sage Open, 10, 3 (2020)

24. J. Atkinson, Developing teams through project-based learning. Hampshire: Gower Publishing (2001) 